\title{
Prevalence, Awareness, Treatment, and Control of Hypertension among Chinese First-Generation Migrants and Italians in Prato, Italy: The CHIP Study
}

\author{
Pietro A. Modesti, ${ }^{1}$ Maria Calabrese, ${ }^{2}$ Ilaria Marzotti, ${ }^{1}$ Hushao Bing, ${ }^{3}$ \\ Danilo Malandrino, ${ }^{1}$ Maria Boddi, ${ }^{1}$ Sergio Castellani, ${ }^{1}$ and Dong Zhao $^{4}$ \\ ${ }^{1}$ Department of Experimental and Clinical Medicine, University of Florence, Florence, Italy \\ ${ }^{2}$ Diabetology Unit, Ospedale Misericordia e Dolce, Prato, Italy \\ ${ }^{3}$ Associazione Culturale Cinese di Fujian in Italia, Prato, Italy \\ ${ }^{4}$ Department of Epidemiology, Capital Medical University Beijing Anzhen Hospital and National Institute of Heart, \\ Lung \& Blood Disease, Beijing, China \\ Correspondence should be addressed to Pietro A. Modesti; pa.modesti@unifi.it
}

Received 29 November 2016; Revised 11 March 2017; Accepted 19 March 2017; Published 13 April 2017

Academic Editor: Tomohiro Katsuya

\begin{abstract}
Copyright (C) 2017 Pietro A. Modesti et al. This is an open access article distributed under the Creative Commons Attribution License, which permits unrestricted use, distribution, and reproduction in any medium, provided the original work is properly cited.
\end{abstract}

\begin{abstract}
Data on health needs of Chinese living in the South of Europe are lacking. To compare prevalence, awareness, treatment, control, and risk factors for hypertension between Chinese migrants and Italian adults, a sample of 1200 first-generation Chinese migrants and 291 native Italians aged 35-59 years living in Prato (Italy) was recruited in a community-based participatory crosssectional survey. Primary outcome measure was hypertension, diagnosed for blood pressure values $\geq 140 / 90 \mathrm{mmHg}$ or current use of antihypertensive medications. Associations with exposures (including age, gender, body mass index, waist, education level, total cholesterol, and triglycerides) were examined using logistic regression. When compared with Italians, Chinese had higher hypertension prevalence $(27.2 \%$ versus $21.3 \%, p<0.01)$, with comparable levels of awareness $(57.4 \%$ and $48.4 \%)$ but lower treatment rates $(70.6 \%$ and $90.0 \%$, resp.). In both ethnic groups age and parental history of hypertension were predictors of awareness and treatment, body mass index being predictor of hypertension diagnosis. In Chinese participants, where the optimum cut-off point for body mass index was $\geq 23.9 \mathrm{~kg} / \mathrm{m}^{2}$, the sensibility and specificity prediction for hypertension were $61.7 \%$ and $59.8 \%$, respectively (area under the ROC curve $=0.629$ ). Implementation of specific, culturally adapted health programs for the Chinese community is now needed.
\end{abstract}

\section{Introduction}

The distribution of cardiovascular risk factors, as well as the benefits of advances in prevention and treatment of chronic disease, are not shared equally across economic and ethnic groups either in the United States [1] or in Europe [2-4]. Cultural factors seem to play a primary role in limiting the efficacy of prevention strategies conceived for the native population in reaching first-generation migrants. This issue is now relevant for most EU countries where immigration flows importantly grew in recent decades [2]. As recently stated by the European Society of Cardiology [5], information on health needs of minority groups living in Europe is now available for subjects originating from Sub-Saharan African countries and South Asia [6,7], whereas data for Chinese are still limited [8]. In recent decades China experienced a rapid increase in stroke incidence [9] and the control of hypertension and other risk factors is now recognized as a public health priority [10-12].

In the last decades migration flows from China to Europe have been mainly directed towards Italy and Spain [13], and Chinese are now the third largest overseas-born population in Italy [14]. In particular, Prato has the highest proportion of Chinese immigrants of any Italian province, subjects being 
mainly occupied in the textiles industry of the area [15]. Risk factor distribution in the Chinese community of Prato was recently investigated in the CHIP (CHinese In Prato) survey which enrolled Chinese first-generation migrants aged 18 to 59 years $[16,17]$. However, data on the differences in hypertension burden between Chinese and Europid adults are lacking. This information is essential for health policies, strategies, and plans [18].

The present study was thus performed (1) to compare the prevalence of hypertension and other main risk factors between first-generation Chinese immigrants and Italian adults in the age group 35 to 59 years; (2) to investigate the relationship of hypertension with obesity indices; and (3) to identify the optimal BMI cut-off value to be adopted for screening purposes.

\section{Methods}

2.1. Setting, Study Design, and Participants. Located in Tuscany, $30 \mathrm{Km}$ far from Florence, Prato has a population of more than 180,000 with a number of Chinese regular residents in the area constantly growing from 169 in 1990 to 15,957 in 2014 [19]. In 2014 the CHIP survey, incorporating principles of community-based participatory research $[20,21]$, was performed. More precisely a community-academic partnership, composed of the Consulate General of Florence, the four local community-based Chinese organizations, and the Chinese and Italian Universities, was built to develop a sensitive, culturally appropriate, no coercive recruitment, and enrolment process [19]. A network sampling procedure was adopted $[16,17,22]$. To be eligible for the present analysis, participants recruited in 2014 had (1) to self-identify to be born in continental China and to have grandparents born in that country; (2) to be between 35 and 59 years of age; and (3) to live permanently in Prato. In 2014 a cohort composed of native Italian population was randomly sampled from General Practice lists stratified by age and gender using an extraction program. Each subject was initially sent a letter informing them about the study, followed by an invitation to attend for screening. Subjects were replaced after two invitations. Those with whom no contact was established after three invitations were sent a letter by recorded delivery mail. Response rate of the eligible Italian subjects approached during recruitment was $67 \%$. Exclusion criteria included pregnant women, critically ill individuals, and impaired cognitive ability as judged by clinical staff members.

2.2. Ethics, Consent, and Permissions. The study was approved by the Ethical Committee of the Azienda Ospedaliero-Universitaria Careggi (Ref. OSS.14.089). Written informed consent was obtained from all participants. Subjects were provided with a written description of the study in their choice of Chinese or Italian and written consent was obtained at time of entry from each participant. Participants with untreated clinical diseases identified during the examinations were advised to see their general practitioner or referred to the Hospital of Prato. No other incentives were offered to study participants. Data collected were anonymous and deidentified. The screening phase was performed between June 2014 and April 2015.

2.3. Data Collection. All participants were instructed to fast overnight before the day of survey. In the early morning (between 07.00 and $10.00 \mathrm{am}$ ) individuals attended the Research Centre where trained Chinese and Italian staff members administered a questionnaire and performed physical (blood pressure and anthropometry) and biochemical blood measurements (glucose, total cholesterol, and triglycerides).

Questionnaire gathered information on participant sociodemographic data, tobacco use, alcohol consumption, medical and reproductive history, medication use, and migration [17].

Blood pressure (BP) was measured three times using a clinically validated semiautomatic digital sphygmomanometer (M6; Omron Matsusaka Co. Ltd., Japan) with appropriate cuff size according to current guidelines [23]. The average of the last two readings was used for analysis. Body weight, height, and waist and hip circumferences were measured according to standardized protocols [24]. Waist-to-hip ratio was calculated as waist circumference $(\mathrm{cm})$ divided by hip circumference $(\mathrm{cm})$. Waist-to-height ratio was calculated as waist circumference $(\mathrm{cm})$ divided by height $(\mathrm{cm})$. Biochemical measurements were performed on finger-prick blood samples using validated dry chemistry methods (AccuChek AVIVA, Roche Diagnostics S.p.A., Mannheim, Germany for glucose and MultiCare-in, HPS, Italy, for total cholesterol and triglycerides) $[25,26]$. Nonfasting participants were asked to return at fast for blood tests. Participants with fasting glucose $\geq 126 \mathrm{mg} / \mathrm{dL}$ were also asked to return for confirmatory testing. All requested participants attended the second visit.

2.4. Diagnostic Criteria. The primary outcome variable was the prevalence of hypertension, defined as systolic $\mathrm{BP} \geq$ $140 \mathrm{mmHg}$, or diastolic BP $\geq 90 \mathrm{mmHg}$, or being on antihypertensive medication [23]. Awareness of hypertension was defined as self-report of any previous diagnosis of hypertension by a healthcare professional among participants with hypertension. Treatment of hypertension was defined as selfreported use of a prescription medication for management of hypertension at the time of survey. Control of hypertension was defined as antihypertensive treatment associated with average systolic and diastolic BP values $<140 \mathrm{mmHg}$ and $<$ $90 \mathrm{mmHg}$, respectively. Blood pressure was stratified according to the recommendations of the $2013 \mathrm{ESH}-\mathrm{ESC}$ guidelines (grades ESH-ESC) [23].

Diagnosis of diabetes mellitus (DM) was based on fasting plasma glucose criteria ( $\geq 126 \mathrm{mg} / \mathrm{dL}$ confirmed by repeat testing) and/or current treatment with glucose-lowering drugs [27]. High cholesterol was classified for total cholesterol levels $\geq 240 \mathrm{mg} / \mathrm{dL}[28,29]$ and high triglycerides for triglycerides levels $\geq 200 \mathrm{mg} / \mathrm{dL}$ [29].

Other exposures included education level (no studies, primary and secondary school, high school, college, or more), alcohol use, smoking (current smokers and noncurrent smokers defined as those who never smoked and former smokers who quit smoking), health insurance (none, registration to 
TABLE 1: Demographic data and selected clinical and laboratory findings in Italian and Chinese participants.

\begin{tabular}{|c|c|c|c|c|}
\hline Variables & Chinese $n=1200$ & Italians $n=291$ & $p$ value & Difference $(95 \% \mathrm{Cl})$ \\
\hline Age (years) & $46.2 \pm 7.1$ & $47.6 \pm 7.5$ & 0.004 & $-1.4(-2.3$ to -0.4$)$ \\
\hline Height $(\mathrm{cm})$ & $163.1 \pm 7.9$ & $171.3 \pm 10.7$ & 0.001 & $-8.1(-9.2$ to -7.0$)$ \\
\hline Weight (kg) & $63.3 \pm 10.7$ & $74.8 \pm 12.2$ & 0.001 & $-11.5(-12.9$ to -10.1$)$ \\
\hline Body mass index $\left(\mathrm{kg} / \mathrm{m}^{2}\right)$ & $23.7 \pm 3.1$ & $25.4 \pm 3.2$ & 0.001 & $-1.7(-2.2$ to -1.3$)$ \\
\hline Hip circumference (cm) & $95.4 \pm 6.4$ & $98.3 \pm 12.2$ & 0.001 & $-2.8(-3.9$ to -1.8$)$ \\
\hline Waist circumferences $(\mathrm{cm})$ & $82.7 \pm 9.5$ & $88.3 \pm 13.3$ & 0.001 & $-5.6(-6.9$ to -4.2$)$ \\
\hline Waist to hip ratio & $0.866 \pm 0.070$ & $0.898 \pm 0.077$ & 0.001 & $-0.032(-0.042$ to -0.023$)$ \\
\hline Systolic BP (mmHg) & $120.5 \pm 19.2$ & $120.4 \pm 13.9$ & 0.889 & $0.2(-2.2$ to 2.5$)$ \\
\hline Diastolic BP (mmHg) & $80.3 \pm 11.7$ & $77.8 \pm 10.9$ & 0.001 & $2.5(1.0$ to 4.0$)$ \\
\hline Heart rate (bpm) & $71.7 \pm 10.2$ & $70.9 \pm 8.8$ & 0.235 & $0.8(-0.5$ to 2.0$)$ \\
\hline Fasting glucose (mg/dL) & $118.3 \pm 33.4$ & $103.6 \pm 12.9$ & 0.001 & 14.7 (10.8 to 18.7$)$ \\
\hline Total cholesterol (mg/dL) & $233.1 \pm 62.0$ & $190.3 \pm 55.5$ & 0.001 & $42.8(35.0$ to 50.6$)$ \\
\hline Triglycerides (mg/dL) & $194.9 \pm 105.9$ & $163.1 \pm 86.8$ & 0.001 & 31.8 (18.6 to 44.9$)$ \\
\hline
\end{tabular}

Values are mean \pm SD.

National Health System, or private), Italian speaking (yes, no), BMI, and waist. For occupational classification of workers (excluding retired and unemployed), "blue collars" (workers who perform manual labors) and "white collar" (workers who perform professional job duties in an office setting) were considered.

2.5. Statistical Analysis. The sample size for comparison of Italian and Chinese groups aged 35-59 years was based on an estimated hypertension prevalence of $20 \%$ in Italian and $29 \%$ in Chinese populations. Considering a 5\% confidence level (alpha error) and 80\% statistical power (beta error), the estimated sample size was at least 281 individuals. Values are expressed as mean \pm standard deviation (SD) or $n$ cases (\%). Analyses were stratified by 5 -year age groups (35-39 years; 40-44 years; $45-49$ years; $50-54$ years; $55-59$ years). Age standardized rates were based on direct standardization using the WHO World Standard Population [30]. Associations of hypertension with exposures were explored with logistic regression analysis. Exposures included age, sex, education categories, current smoking, high total cholesterol, high triglycerides, BMI, and waist-hip ratio tertiles (defined separately for each sex and ethnic group). When appropriate, test of hypothesis was done at significance level 0.05 two-sided. For regression analysis ORs and 95\% CI were calculated. Receiver operating characteristics (ROC) curves for hypertension or undiagnosed hypertension and the areas under the curve were then calculated for BMI with corresponding 95\% confidence intervals. The largest sensitivity-specificity product value obtained from each ROC curve was calculated. IBM SPSS software (version 22.0, SPSS Inc., Chicago, Illinois, USA) was used for analysis.

\section{Results}

3.1. Characteristics of Participants. Overall, 1200 Chinese and 291 Italian participants were investigated for the present study. Chinese participants had left China at an average age of $34.6 \pm 8.2$ years. Only $17.0 \%$ had lived in China urban areas, the large majority $(83.0 \%)$ coming from rural China. In the Chinese cohort 201 subjects did not complete primary education, this condition being more prevalent among women than men (OR 2.35; 95\% CI 1.69 to 3.27). Participants able to speak Italian were $29 \%$ with no differences by gender. Only $23 \%$ of investigated subjects had access to health services on a par with Italian citizens (subscription to the Regional Health System) with no differences by gender. Other $19 \%$ of participants self-reported the attribution of the Temporary Present Foreigner code with free temporary access (1 year) to healthcare. However, the large majority (58\%) had no free access to the healthcare (private or public). Chinese participants were mainly occupied in light manual works in the textile industry $(n=1119,93 \%)$, only a minority being housekeepers ( $n=29 ; 2.4 \%)$, or manager or self-employed professionals ( $n=18 ; 1.5 \%)$. Conversely, in the Italian cohort, only 60 participants (21\%) were manual workers, 126 were manager or self-employed professionals (43.3\%), and 87 (29.9\%) were white-collar office worker. Participants unemployed and seeking work were $2(0.2 \%)$ and $6(2.1 \%)$ in the Chinese and Italian cohort, respectively. Overall, 450 out of the 635 women $(71 \%)$ in the Chinese cohort had at least one previous abort for unwanted pregnancy versus 27 out of the 149 women $(18 \%)$ of the Italian cohort (chi-square test, $p<$ 0.001).

Main measurements in Italian and Chinese study participants are reported in Table 1 . Chinese were significantly shorter and lighter and had lower BMIs than the Italian participants. Waist and hip circumferences and waist-to-hip ratio were also significantly smaller in Chinese. However, mean levels of diastolic BP, fasting glucose, total cholesterol, and triglycerides were significantly higher in Chinese than in Italian participants (Table 1).

3.2. Hypertension Burden in the Chinese and Italian Cohorts. Overall, hypertension was diagnosed in 326 and 62 subjects among Chinese and Italian participants $(27.2 \%$ and $21.3 \%$, 


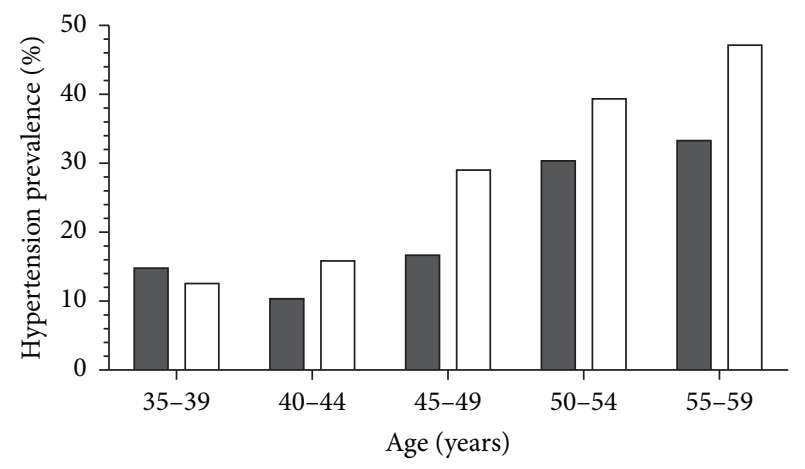

$\begin{array}{lccccc}\text { Italians }(n) & & & & \\ \text { At risk } & 54 & 58 & 60 & 56 & 63 \\ \text { Cases } & 8 & 6 & 10 & 17 & 21 \\ \text { Chinese }(n) & & & & \\ \text { At risk } & 263 & 252 & 279 & 249 & 157 \\ \text { Cases } & 33 & 40 & 81 & 98 & 74 \\ & \square \text { Italians (age stand. prev. 19.9\%; 95\% } \mathrm{Cl} \mathrm{18.0} \mathrm{to} \mathrm{21.8)} \\ \square & \text { Chinese (age stand. prev. 25.3\%; } 95 \% \mathrm{Cl} 24.3 \text { to 26.4) }\end{array}$

FIGURE 1: Age specific and age standardized (to WHO population 2001) prevalence of hypertension in the CHIP study population aged 35 to 59 years.

resp.). Age specific hypertension prevalence is reported in Figure 1. Age standardized prevalence was 25.3\% (95\% Cl 24.3 to 26.4$)$ and $19.9 \%$ (95\% Cl 18.0 to 21.8$)$ in the Chinese and Italian cohorts, respectively. In the Italian cohort all the 62 participants with hypertension had Grade 1 HT whereas, in the Chinese cohort, 66 (24\%) and 20 participants (7\%) had Grade 2 and Grade 3 HT, respectively. Participants with hypertension aware of their condition were 187 (57.4\%) in the Chinese and $30(48.4 \%)$ in the Italian cohort (age- and sex-adjusted OR 1.53 ; $95 \% \mathrm{Cl} 0.88$ to 2.66 ). Although Chinese with hypertension aware of their condition were less frequently treated with drugs than native Italians $(n=132$; $70.6 \%$ and $n=27 ; 90.0 \%$, resp.; age- and sex-adjusted OR $0.23 ; 95 \% \mathrm{Cl} 0.06$ to 0.85$)$, the rate of $\mathrm{BP}$ control did not differ between the two groups ( $n=56,42 \%$ and $n=12,44 \%$ in the Chinese and Italian Cohort, resp.; age- and sex-adjusted OR $0.91 ; 95 \% \mathrm{Cl} 0.39$ to 2.13 ). Among subjects with hypertension belonging to the Chinese cohort, the use of antihypertensive drugs was independent from the registration to the Regional Healthcare system.

Prevalence of all main risk factors was higher in the Chinese than in the Italian cohort (Figure 2) (Table 2). The OR for hypertension (Chinese versus Italians) further increased when education and work categories were included in the model (Model 2). When controlling also for obesity indices and other exposures a further increase was observed (Model 3) (Table 2).

At adjusted multivariable logistic regression only body mass index was associated with hypertension in both ethnic groups (Table 3). The overall ability of body mass index to correctly identify Chinese subjects with both hypertension and undiagnosed hypertension in the Chinese cohort was finally assessed with ROC curves. In the whole Chinese cohort, where the optimum cut-off points for body mass index were $\geq 23.9 \mathrm{~kg} / \mathrm{m}^{2}$, the sensibility and specificity prediction for

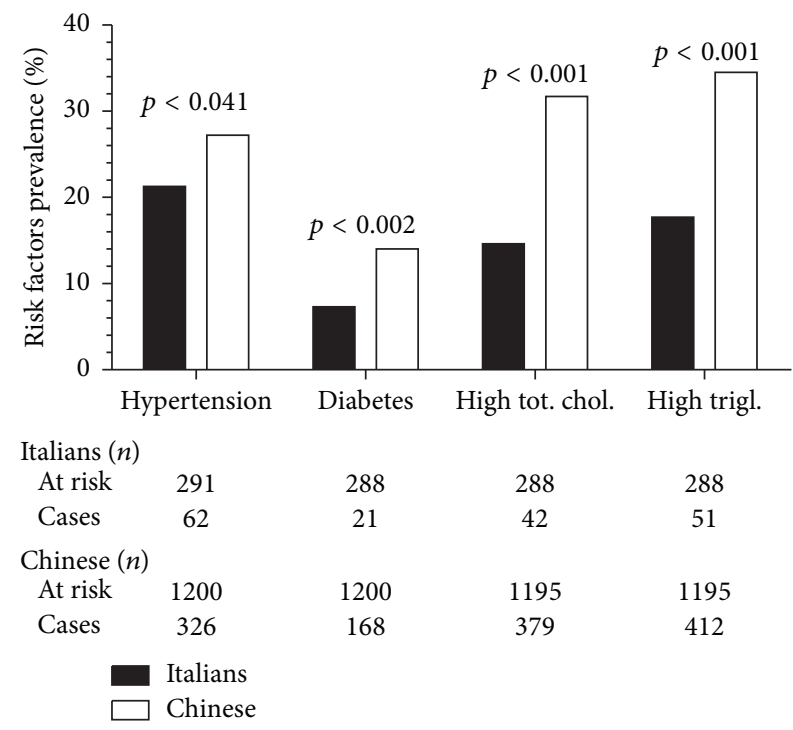

Figure 2: Prevalence of hypertension, diabetes, hypercholesterolemia (total cholesterol $\geq 240 \mathrm{mg} / \mathrm{dL}$ ), and hypertriglyceridemia (triglycerides $\geq 200 \mathrm{mg} / \mathrm{dL}$ ) in the Chinese and Italian cohorts.

hypertension were $61.7 \%$ and $59.8 \%$, respectively (Table 4). The areas under the ROC curves of body mass index for hypertension prediction were 0.629 and 0.597 in the whole Chinese cohort and among Chinese unaware of hypertension, respectively.

\section{Discussion}

According to the present findings, first-generation Chinese immigrants have a higher prevalence of hypertension and main risk factors than the Italian population independently from socioeconomic conditions. Around 2.8 million Chinese citizens currently reside legally in Council of Europe member States, with the largest groups being in Italy, France, Russia, and the United Kingdom. In the last two decades the presence of Chinese remained almost stable in Northern Europe whereas it importantly increased in Italy, mostly in the textile industry area near Florence. The limited studies comparing health needs of Chinese and Europid populations highlight the strength of the present study. In the Health Survey for England [31] the Chinese community living in UK had a prevalence of hypertension which was comparable to values we found in Chinese living in Italy. The characteristics of the two communities may differ, because the Chinese community now living in Prato is mainly composed of subjects born in China whereas most Chinese participants investigated in UK were born in Europe. On the other hand hypertension in the Europid cohort was more prevalent in UK than in Italy, so that, differently from what observed in UK [31], Chinese in Prato had higher prevalence of hypertension than native Italian population. These findings might let us hypothesize that Chinese migrants do not alter their original habits to follow the habits of the host country. In the same line it is to be considered that, among subjects with hypertension belonging to the Chinese cohort, the use of antihypertensive drugs was 
TABLE 2: Odds ratios (95\% CI) for different factors (Chinese versus Italians).

\begin{tabular}{|c|c|c|c|}
\hline & $\begin{array}{c}\text { Model } 1 \\
\text { OR }(95 \% \mathrm{Cl})\end{array}$ & $\begin{array}{c}\text { Model } 2 \\
\text { OR }(95 \% \mathrm{Cl})\end{array}$ & $\begin{array}{c}\text { Model } 3 \\
\text { OR }(95 \% \mathrm{Cl})\end{array}$ \\
\hline Smoke (past or current) & $0.62(0.43$ to 0.89$)$ & $0.64(0.38$ to 1.10$)$ & $0.74(0.41$ to 1.35$)$ \\
\hline Alcohol (yes) & $0.37(0.28$ to 0.50$)$ & $0.45(0.28$ to 0.71$)$ & $0.38(0.22$ to 0.66$)$ \\
\hline Body mass index & $0.86(0.82$ to 0.89$)$ & $0.85(0.79$ to 0.91$)$ & $0.93(0.90$ to 0.97$)$ \\
\hline Waist & $0.95(0.93$ to 0.96$)$ & $0.94(0.92$ to 0.96$)$ & 1.03 (0.91 to 1.17$)$ \\
\hline Total cholesterol $\geq 240 \mathrm{mg} / \mathrm{dL}$ & 3.07 (2.13 to 4.42$)$ & $2.36(1.32$ to 4.20$)$ & $1.65(0.87$ to 3.13$)$ \\
\hline Triglycerides $\geq 200 \mathrm{mg} / \mathrm{dL}$ & $2.84(2.01$ to 4.00$)$ & $2.97(1.70$ to 5.19$)$ & $2.20(1.18$ to 4.09$)$ \\
\hline Hypertension & $1.61(1.16$ to 2.24$)$ & $2.65(1.47$ to 4.76$)$ & $3.44(1.71$ to 6.94$)$ \\
\hline
\end{tabular}

Model 1 adjusted for age and sex.

Model 2 adjusted for age, sex, education, and work.

Model 3 adjusted for age, sex, education, work, and all exposures included in the table.

TABLE 3: Association between exposures and hypertension at multivariate logistic regression (adjusted for all exposures reported in the table) performed among Chinese and Italian participants.

\begin{tabular}{|c|c|c|c|c|c|}
\hline \multirow{2}{*}{ Ethnicity } & \multirow{2}{*}{ Exposures } & \multicolumn{2}{|c|}{ All subjects } & \multicolumn{2}{|c|}{ Not aware of hypertension } \\
\hline & & OR $(95 \% \mathrm{Cl})$ & $p<$ & OR $(95 \% \mathrm{Cl})$ & $p<$ \\
\hline \multirow{6}{*}{ Chinese } & Age (years) & $1.09(1.07$ to 1.12$)$ & 0.001 & $1.06(1.03$ to 1.10$)$ & 0.001 \\
\hline & Gender (male) & $1.00(0.73$ to 1.37$)$ & 0.988 & 1.04 (0.68 to 1.58$)$ & 0.873 \\
\hline & Education level & 1.01 (0.83 to 1.23$)$ & 0.960 & $1.01(0.78$ to 1.32$)$ & 0.935 \\
\hline & Work (white collar) & $1.94(0.95$ to 3.97$)$ & 0.070 & $3.00(1.34$ to 6.75$)$ & 0.008 \\
\hline & Body mass index $\left(\mathrm{kg} / \mathrm{m}^{2}\right)$ & 1.11 (1.04 to 1.19$)$ & 0.002 & $1.09(1.00$ to 1.20$)$ & 0.050 \\
\hline & Waist $(\mathrm{cm})$ & 1.02 (1.00 to 1.05$)$ & 0.091 & $1.01(0.98$ to 1.05$)$ & 0.460 \\
\hline \multirow{6}{*}{ Italians } & Age (years) & $1.03(0.99$ to 1.08$)$ & 0.184 & $1.00(0.93$ to 1.06$)$ & 0.865 \\
\hline & Gender (male) & $1.23(0.63$ to 2.40$)$ & 0.546 & $1.53(0.63$ to 3.73$)$ & 0.348 \\
\hline & Education level & $0.75(0.41$ to 1.38$)$ & 0.358 & $0.83(0.36$ to 1.90$)$ & 0.657 \\
\hline & Work (white collar) & 1.10 (0.49 to 2.47$)$ & 0.817 & $0.63(0.24$ to 1.69$)$ & 0.363 \\
\hline & Body mass index $\left(\mathrm{kg} / \mathrm{m}^{2}\right)$ & $1.26(1.13$ to 1.41$)$ & 0.001 & 1.28 (1.11 to 1.47$)$ & 0.001 \\
\hline & Waist $(\mathrm{cm})$ & $0.99(0.96$ to 1.01$)$ & 0.323 & $0.97(0.94$ to 1.00$)$ & 0.056 \\
\hline
\end{tabular}

TABLE 4: Areas (with 95\% confidence intervals) under the receiver operating curves and cut-off values for body mass index, for identifying hypertension in the whole Chinese cohort and in Chinese participants unaware of hypertension.

\begin{tabular}{lcccccccc}
\hline \multirow{2}{*}{ Sex } & \multicolumn{4}{c}{ All Chinese participant } & \multicolumn{3}{c}{ Chinese participants unaware of hypertension } \\
& Area & SE & (Area 95\% CI) & Cut-off & Area & SE & (Area 95\% CI) & Cut-off \\
\hline Men & 0.621 & 0.027 & $(0.568$ to 0.673$)$ & 24.0 & 0.570 & 0.039 & $(0.494$ to 0.646$)$ & 23.8 \\
Women & 0.634 & 0.024 & $(0.586$ to 0.681$)$ & 23.9 & 0.619 & 0.033 & $(0.554$ to 0.685$)$ & 23.6 \\
All & 0.629 & 0.018 & $(0.593$ to 0.664$)$ & 23.9 & 0.597 & 0.025 & $(0.548$ to 0.647$)$ & 23.7 \\
\hline
\end{tabular}

independent from the registration to the Regional Healthcare system or the capability to speak Italian. In particular rate of treatment was lower in the Chinese than in the Italian cohort, despite comparable levels of hypertension awareness. Specific prevention strategies have thus to be implemented in the Chinese community. Investing in a multiethnic perspective is thus necessary for eliminating inequities in risk factor control because prevention programs addressed to resident population might be inefficient for ethnic minorities [18, 32].

It has been consistently reported that risk factor distribution and health needs among different populations are markedly influenced by socioeconomic conditions [1]. The socioeconomic differences of the two investigated populations might influence observed results. In the present study Chinese participants were manual workers with low education level, mostly coming from rural China. The Italian sample is mainly composed of middle-class citizens. The two samples can be considered representatives of the two ethnic groups living in Prato. However, when socioeconomic indicators (education level and work) were included in the model the OR of Chinese for hypertension further increased. It is therefore conceivable that additional factors might play a 
role. Specific investigations on nutritional habits and sodium consumption are needed.

Overweight and obesity are established risk factors for hypertension $[33,34]$. In the present survey BMI rather than central obesity was independently associated with hypertension in both Chinese and Italian cohort. Most importantly, notwithstanding the significantly higher prevalence of hypertension and other risk factors in Chinese than in the Italian cohort, Chinese participants were found to have markedly lower mean BMIs than the Italians. It is noteworthy that in Chinese participants the higher BMI was associated with hypertension with a cut-off value of $24 \mathrm{~kg} / \mathrm{m}^{2}$. The WHO consultation group indeed recommended a lower cut-off of BMI for Asian with respect to native European populations [35] and the identified diagnostic cut-off for overweight in Chinese was $24 \mathrm{~kg} / \mathrm{m}^{2}$ [36]. This information is important in the light of prevention because the different cut-off value for obesity have to be adopted by physicians who are facing the new patients [37]. The existence of a distinct cut-off value is also to be communicated within the Chinese community because the emulation of native population might lead migrants to increased risk.

\section{Study Limitations}

This study has several potential limitations.

First, the study design was cross-sectional, so we cannot conclude the cause-effect relationship.

Second, we are aware that the inclusion of undocumented migrants in the present surveys bears limitations. This group is usually excluded from epidemiological studies and surveys because the ability to go back to a list of individuals in some form is lacking. This is the reason why the sampling method of the study subjects differed between Chinese immigrants and Italian inhabitants. On this basis, it would be inappropriate to compare the two groups. However, in consideration of the limited availability of data regarding Chinese migration to the South of Europe, of the high presence of this ethnic group in the area, and of the fact that most EU countries currently offer emergency care to undocumented migrants, current insight on specific health needs of Chinese population in Italy might be important to offer health authority the opportunity to launch specific health programs [18]. The direct participation of the whole Chinese Community in the present shared project following the principles of a participatory research is to be acknowledged representing a proof of their willingness to collaborate in future actions of screening within the community.

Third, the sample size of Italians was limited to fully investigate age- and sex-stratified associations. In addition present survey investigated subjects in work ages of 35 to 59 years. We are aware that additional studies with larger sample sizes are needed to evaluate ethnic differences in hypertension burden, particularly at older ages. However, the creation of a cohort composed by young and middle aged subjects may offer the opportunity to follow these subjects in the future and to investigate the transition to the process of care in the Chinese community.

\section{Conclusions}

This study shows a high prevalence of hypertension and other main risk factors among young and middle-aged firstgeneration Chinese migrants settled in Italy. Present findings provide health authority useful information to respond to health needs of Chinese community and develop upstream specific preventive strategies.

\section{Disclosure}

The design and conduct of the study; collection, management, analysis, and interpretation of the data; preparation, review, and approval of the manuscript; and decision to submit the manuscript for publication were the responsibilities of the authors alone and independent of the funder.

\section{Conflicts of Interest}

The authors declare that they have no conflicts of interest.

\section{Authors' Contributions}

Pietro A. Modesti conceived, designed, and coordinated the study, performed data analysis, and drafted the manuscript; Maria Calabrese, Ilaria Marzotti, Sergio Castellani, Maria Boddi, and Dong Zhao were involved in conception and design of the study and contributed to the interpretation of data; Dong Zhao oversaw the Chinese version of the questionnaire and provided substantial contribution in data analysis and interpretation of findings. All authors had full access to all the data in the study, revised the manuscript critically for important intellectual content, and gave the final approval of the version to be published. Pietro A. Modesti is the guarantor.

\section{Acknowledgments}

The authors thank all the Chinese individuals who participated in the study; Dr. Wang Fuguo (Consul General of the People's Republic of China), Dr. Wang Jian (Consul), and Mr. Chen Hong Sheng (Friendship Association of Chinese in Prato) for providing the necessary support to interact with the Chinese Community; and Eleonora Perruolo, Jing Yang, Wang Xiaoling, Zhang Mengyue, Yang Zihua, Guo Jia, Lara Bini, Maira Camera, and Sonia Fligor for their contribution in the acquisition of data. This study was supported by grant from the Regione Toscana.

\section{References}

[1] E. P. Havranek, M. S. Mujahid, D. A. Barr et al., "Social determinants of risk and outcomes for cardiovascular disease: a scientific statement from the American Heart Association," Circulation, vol. 132, no. 9, pp. 873-898, 2015.

[2] B. Rechel, P. Mladovsky, D. Ingleby, J. P. Mackenbach, and M. McKee, "Migration and health in an increasingly diverse Europe," The Lancet, vol. 381, no. 9873, pp. 1235-1245, 2013.

[3] R. Bhopal, L. Hayes, M. White et al., "Ethnic and socio-economic inequalities in coronary heart disease, diabetes and risk 
factors in Europeans and South Asians," Journal of Public Health Medicine, vol. 24, no. 2, pp. 95-105, 2002.

[4] J. Lindstrom, A. Neumann, K. E. Sheppard et al., "Take action to prevent diabetes - the IMAGE toolkit for the prevention of type 2 diabetes in Europe," Hormone and Metabolic Research, vol. 42, pp. S37-S55, 2010.

[5] M. F. Piepoli, AW. Hoes, S. Agewall et al., "2016 European Guidelines on cardiovascular disease prevention in clinical practice: The Sixth Joint Task Force of the European Society of Cardiology and Other Societies on Cardiovascular Disease Prevention in Clinical Practice (constituted by representatives of 10 societies and by invited experts)Developed with the special contribution of the European Association for Cardiovascular Prevention \& Rehabilitation (EACPR)," European Heart Journal, vol. 37, pp. 2315-2381, 2016.

[6] P. A. Modesti, G. Reboldi, F. P. Cappuccio et al., "Panethnic differences in blood pressure in Europe: a systematic review and meta-analysis," PLoS ONE, vol. 11, no. 1, Article ID e0147601, 2016.

[7] K. A. C. Meeks, D. Freitas-Da-Silva, A. Adeyemo et al., "Disparities in type 2 diabetes prevalence among ethnic minority groups resident in Europe: a systematic review and meta-analysis," Internal and Emergency Medicine, vol. 11, no. 3, pp. 327-340, 2016.

[8] Z. Gong and D. Zhao, "Cardiovascular diseases and risk factors among Chinese immigrants," Internal and Emergency Medicine, vol. 11, no. 3, pp. 307-318, 2016.

[9] D. Zhao, J. Liu, W. Wang et al., "Epidemiological transition of stroke in China: twenty-oneyear observational study from the sino-MONICA-Beijing project," Stroke, vol. 39, no. 6, pp. 16681674, 2008.

[10] W. Yang, J. Lu, J. Weng et al., "Prevalence of diabetes among men and women in China," The New England Journal of Medicine, vol. 362, no. 12, pp. 1090-1101, 2010.

[11] Y. Xu, L. Wang, J. He et al., "Prevalence and control of diabetes in Chinese adults," JAMA, vol. 310, no. 9, pp. 948-959, 2013.

[12] D. Zhao, J. Liu, W. Xie, and Y. Qi, "Cardiovascular risk assessment: a global perspective," Nature Reviews Cardiology, vol. 12, no. 5, pp. 301-311, 2015.

[13] K. Latham and $\mathrm{B}$. Wu, Chinese Immigration into the EU: New Trends, Dynamics and Implications, Europe China Research and Advice Network, London, UK, 2013.

[14] R. Testa, A. R. Bonfigli, S. Genovese, and A. Ceriello, "Focus on migrants with type 2 diabetes mellitus in European Countries," Internal and Emergency Medicine, vol. 11, no. 3, pp. 319-326, 2016.

[15] Y. Gao, Concealed Chains: Labour Exploitation and Chinese Migrants in Europe, International Labour Office, Geneva, Switzerland, 2010.

[16] P. A. Modesti, M. Calabrese, D. Malandrino, A. Colella, G. Galanti, and D. Zhao, "New findings on type 2 diabetes in firstgeneration Chinese migrants settled in Italy: Chinese in Prato (CHIP) cross-sectional survey," Diabetes/Metabolism Research and Reviews, vol. 33, no. 2, 2017.

[17] P. A. Modesti, M. Calabrese, E. Perruolo et al., "Sleep history and hypertension burden in first-generation Chinese migrants settled in Italy: the CHIinese in prato cross-sectional survey," Medicine, vol. 95, no. 14, Article ID e3229, 2016.

[18] P. A. Modesti, F. Perticone, G. Parati, E. Agabiti Rosei, and D. Prisco, "Chronic disease in the ethnic minority and migrant groups: time for a paradigm shift in Europe," Internal and Emergency Medicine, vol. 11, no. 3, pp. 295-297, 2016.
[19] P. A. M. Modesti, Y. Han, Y. Jing et al., "Design and arrangement of the CHIP (CHinese In Prato) study," Epidemiologia e Prevenzione, vol. 38, no. 6, pp. 357-363, 2014.

[20] C. R. Horowitz, M. Robinson, and S. Seifer, "Community-based participatory research from the margin to the mainstream are researchers prepared?" Circulation, vol. 119, no. 19, pp. 26332642, 2009.

[21] C. R. Horowitz, B. L. Brenner, S. Lachapelle, D. A. Amara, and G. Arniella, "Effective recruitment of minority populations through community-led strategies," American Journal of Preventive Medicine, vol. 37, no. 6, pp. S195-S200, 2009.

[22] J. Font and M. Méndez, Surveying Ethnic Minorities and Immigrant Populations. Methodological Challenges and Research Strategies, Amsterdam University Press, Amsterdam, The Netherlands, 2013.

[23] G. Mancia, R. Fagard, K. Narkiewicz et al., "2013 ESH/ESC Guidelines for the management of arterial hypertension: the Task Force for the management of arterial hypertension of the European Society of Hypertension (ESH) and of the European Society of Cardiology (ESC)," Journal of Hypertension, vol. 31, pp. 1281-1357, 2013.

[24] P. A. Modesti, P. Agostoni, C. Agyemang et al., "Cardiovascular risk assessment in low-resource settings: a consensus document of the European Society of Hypertension Working Group on Hypertension and Cardiovascular Risk in Low Resource Settings," Journal of Hypertension, vol. 32, no. 5, pp. 951-960, 2014.

[25] S. Rapi, C. Bazzini, C. Tozzetti, V. Sbolci, and P. A. Modesti, "Point-of-care testing of cholesterol and triglycerides for epidemiologic studies: evaluation of the multicare-in system," Translational Research, vol. 153, no. 2, pp. 71-76, 2009.

[26] G. Freckmann, C. Schmid, S. Pleus et al., "System accuracy evaluation of systems for pointof- care testing of blood glucose: a comparison of a patient-use system with six professional-use systems," Clinical Chemistry and Laboratory Medicine, vol. 52, no. 7, pp. 1079-1086, 2014.

[27] American Diabetes Association, "2. Classification and Diagnosis of Diabetes," Diabetes Care, vol. 39, supplement 1, pp. S13S22, 2016.

[28] J. He, D. Gu, K. Reynolds et al., "Serum total and lipoprotein cholesterol levels and awareness, treatment, and control of hypercholesterolemia in China," Circulation, vol. 110, no. 4, pp. 405-411, 2004

[29] National Cholesterol Education Program (NCEP) Expert Panel on Detection, Evaluation, and Treatment of High Blood Cholesterol in Adults (Adult Treatment Panel III), "Third Report of the National Cholesterol Education Program (NCEP) Expert Panel on Detection, Evaluation, and Treatment of High Blood Cholesterol in Adults (Adult Treatment Panel III) final report," Circulation, vol. 106, no. 25, pp. 3143-3421, 2002.

[30] O. B. Ahmad, C. Boschi-Pinto, A. D. Lopez, C. J. L. Murray, R. Lozano, and M. Inoue, Age Standardization of Rates: A New WHO Standard, World Health Organization, 2001.

[31] P. Zaninotto, J. Mindell, and V. Hirani, "Prevalence of cardiovascular risk factors among ethnic groups: results from the Health Surveys for England," Atherosclerosis, vol. 195, no. 1, pp. e48-e57, 2007.

[32] D. Shi, J. Li, Y. Wang et al., "Association between health literacy and hypertension management in a Chinese community: a retrospective cohort study," Internal and Emergency Medicine, 2017. 
[33] J. A. Cutler, P. D. Sorlie, M. Wolz, T. Thom, L. E. Fields, and E. J. Roccella, "Trends in hypertension prevalence, awareness, treatment, and control rates in United States adults between 1988-1994 and 1999-2004," Hypertension, vol. 52, no. 5, pp. 818827, 2008.

[34] T. A. Kotchen, "Obesity-related hypertension: epidemiology, pathophysiology, and clinical management," American Journal of Hypertension, vol. 23, no. 11, pp. 1170-1178, 2010.

[35] WHO, "Appropriate body-mass index in Asian populations and its implications for policy and intervention strategies," Lancet, vol. 363, p. 902, 2004.

[36] Z. Bei-Fan, "Predictive values of body mass index and waist circumference for risk factors of certain related diseases in Chinese adults: study on optimal cut-off points of body mass index and waist circumference in Chinese adults," Asia Pacific Journal of Clinical Nutrition, vol. 11, pp. S685-S693, 2002.

[37] P. A. Modesti, G. Galanti, P. Cala, and M. Calabrese, "Lifestyle interventions in preventing new type 2 diabetes in Asian populations," Internal and Emergency Medicine, vol. 11, no. 3, pp. 375-384, 2016. 


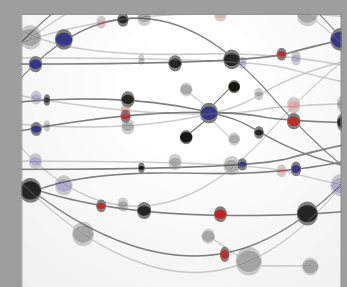

The Scientific World Journal
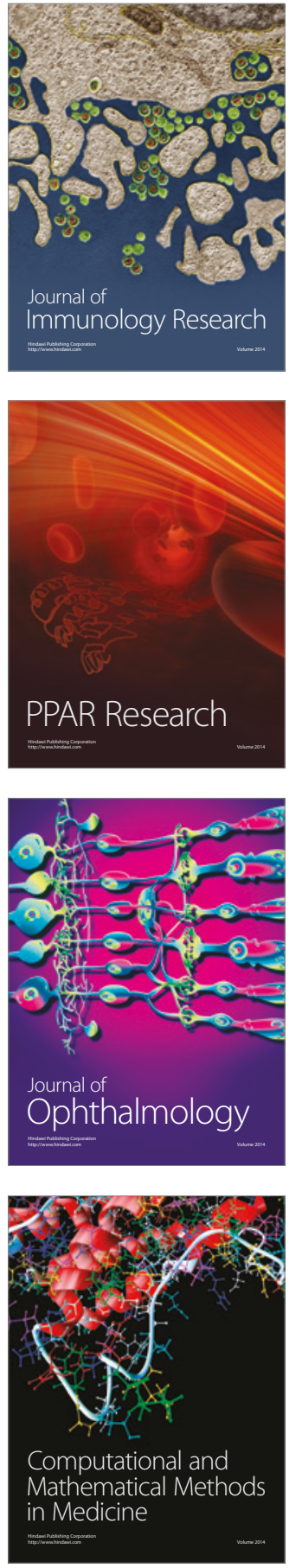

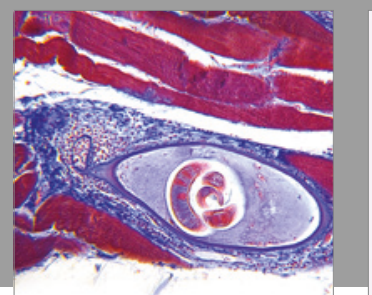

Gastroenterology Research and Practice
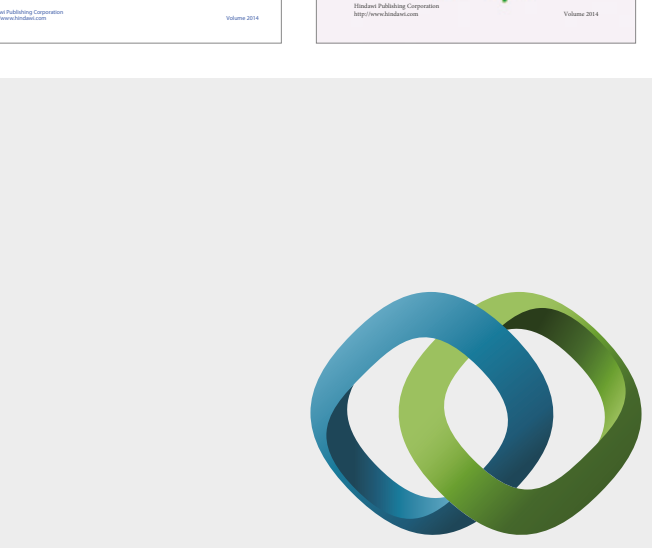

\section{Hindawi}

Submit your manuscripts at

https://www.hindawi.com
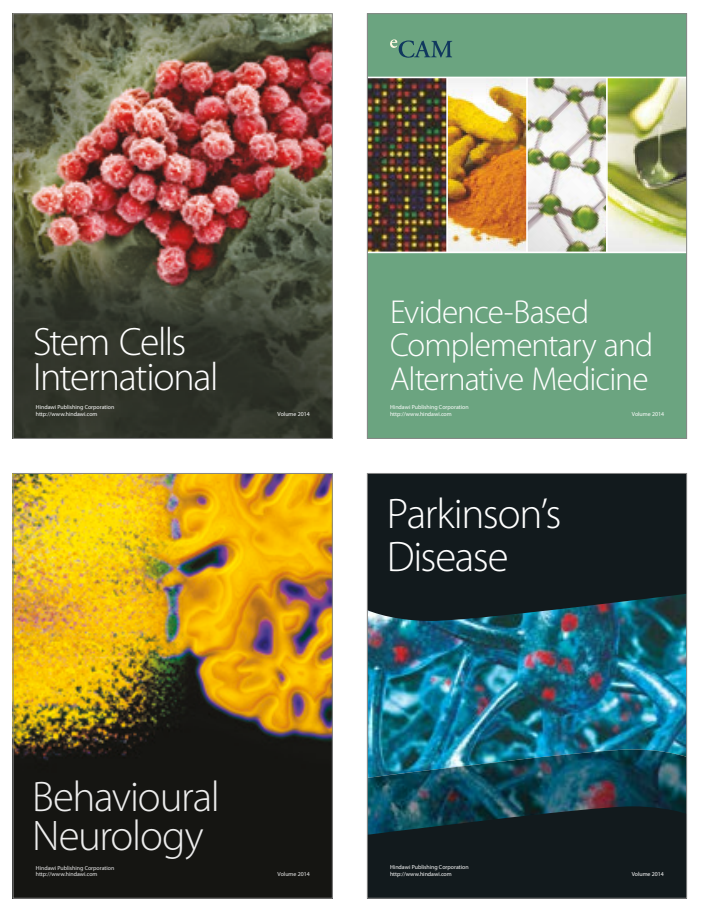
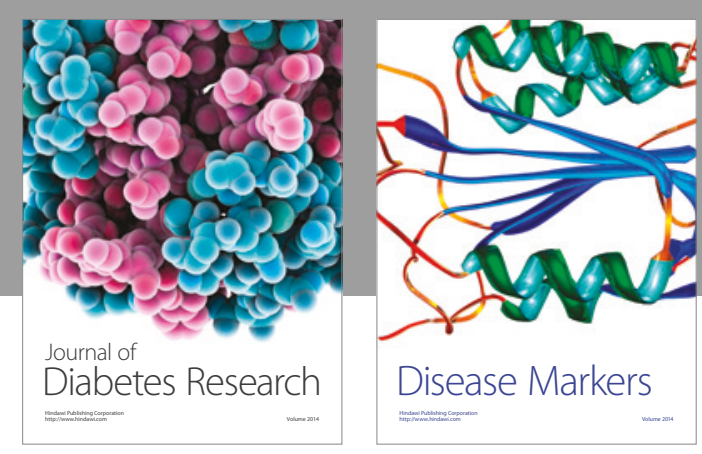

Disease Markers
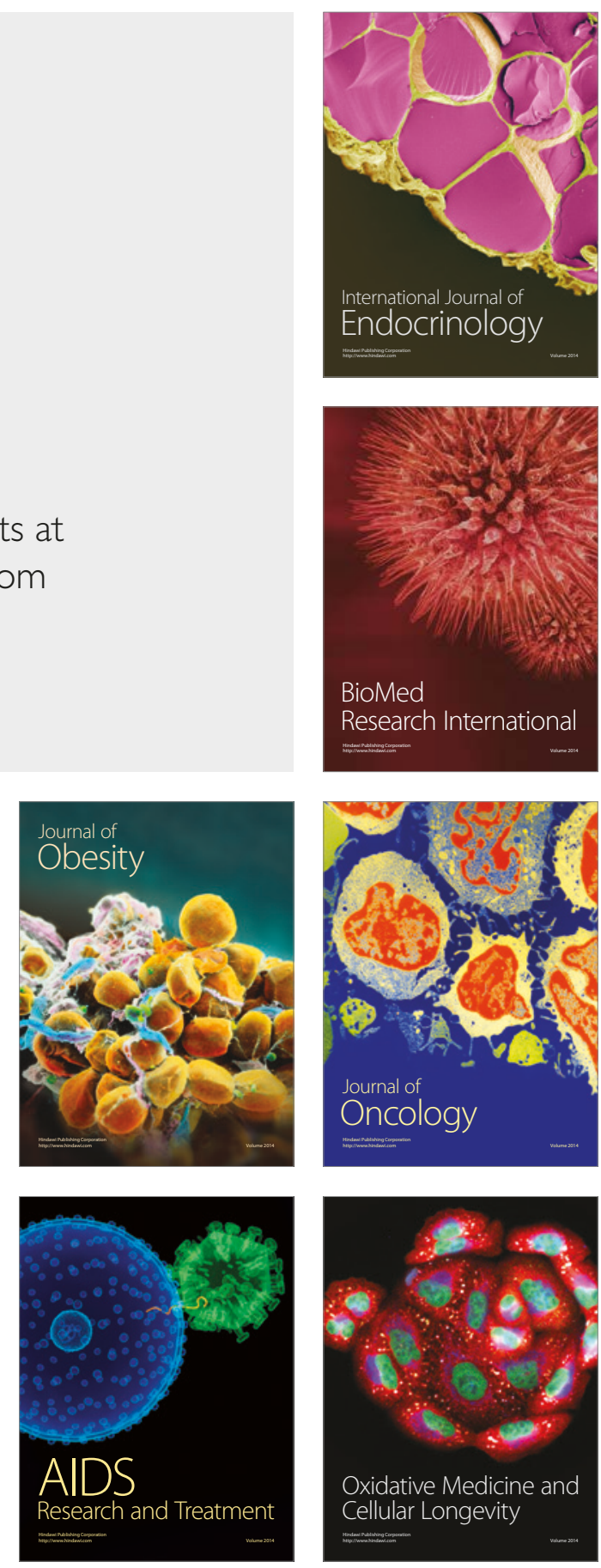